\title{
Osmotic dehydration effects on mass transfer kinetics and characteristics of fried banana (Musa balbisiana) chips
}

\author{
Gustavo Polo-Ruiz, B.Sc. ${ }^{1}$; Sheyla Murga-Mendoza, B.Sc. ${ }^{1}$, Karol Obando-Amaya B.Sc. ${ }^{1}$, Leslie Lescano M.Sc. ${ }^{2}$; \\ Guillermo Linares, Dr. ${ }^{2}$, Jesús Sanchez-Gonzalez, M.Sc. ${ }^{2}$; Meliza Lindsay Rojas, Dr. ${ }^{3 *}$ \\ ${ }^{1}$ Escuela de Ingeniería Agroindustrial, Departamento de Ciencias Agroindustriales, Universidad Nacional de Trujillo, Trujillo. \\ ${ }^{2}$ Departamento de Ciencias Agroindustriales, Universidad Nacional de Trujillo, Trujillo, llescano@unitru.edu.pe, \\ jsanchezg@unitru.edu.pe, glinares@unitru.edu.pe. \\ ${ }^{3}$ Dirección de Investigación y Desarrollo, Universidad Privada del Norte, Trujillo, meliza.rojas@upn.edu.pe. \\ *Corresponding author: meliza.rojas@upn.edu.pe; Av. Del Ejército 920, Trujillo, Perú.
}

\begin{abstract}
This study evaluated the osmotic dehydration (OD) treatments (using sucrose at $60{ }^{\circ} \mathrm{Brix}$ and a solution of salt $1.5 \%$ $(\mathrm{m} / \mathrm{m})$ with sucrose at $\left.45^{\circ} \mathrm{Brix}\right)$ in banana slices. The effects on the mass transfer kinetics (water loss and solids gain) were evaluated and described using the Page, Weibull, Peleg, Azuara, and Lewis mathematical models. Besides, the effect of $O D$ on fat content, instrumental colour, and sensorial attributes was assessed after the frying process. The results showed that water loss occurs firstly and more quickly than solids gain. At the end of $O D$, the highest water loses ( $0.31 \mathrm{~g}$ water $/ \mathrm{g}$ sample) and solids gain $(0.42 \mathrm{~g}$ solid/g sample) were reached using sucrose OD treatment. The water loss and solid gain behaviour were described not only by the kinetics parameters but also by equilibrium parameters values of mathematical models. Furthermore, after frying, the Control samples presented a fat content of $15.5 \pm 0.3 \%$, where the moisture reduction during $O D$ allowed to obtain fried samples with lower fat content $(9.8 \pm 0.3 \%)$, as well as, their instrumental colour was significantly affected mainly decreasing the lightness. Regarding sensorial attributes of fried chips, it was preferred the colour and flavour of samples with sucrose OD treatment, however, the Control samples obtained the best scores in texture attribute. Therefore, it was demonstrated that mass transfer of water and solid during osmotic dehydration treatments did not occur similarly and there were influenced by the concentration and type of osmotic solution. In addition, the modifications in structure and composition during osmotic treatments allowed to obtain a low-fat product with good sensorial attributes.

Keywords-- fat content, colour, osmotic solutions, frying, water loss kinetics, solids gain kinetics.
\end{abstract}

\section{INTRODUCTION}

Banana is a product of great worldwide acceptance, valued as a basic food product in many developing countries and as a product for exportation. It should be noted that Bananas are predominantly produced in Asia, Latin America and Africa [1]. In recent years, the consumption of processed foods has increased, gaining a position in the world market due to changes in consumer preferences. Modern society is looking for foods that are easy to buy, of fast consumption and that at the same time it should be healthy. In this regard, snacks with good sensorial and nutritional properties are a good option to face the actual consumer requirements [2]. Although different processed products can be obtained, the banana fruits are essentially for fresh consumption. Due to its

Digital Object Identifier (DOI):

http://dx.doi.org/10.18687/LACCEI2020.1.1.102

ISBN: 978-958-52071-4-1 ISSN: 2414-6390 high degree of consumption and properties, it represents an interesting raw material to be processed, seeking to reduce the causes of deterioration, and offering product diversification [3].

One option for processing banana is by frying to produce banana chips, which is a source of energy and minerals such as potassium and phosphorous [4]. Frying is one of the oldest and most used techniques in food processing in which high temperatures are used $\left(160{ }^{\circ} \mathrm{C}-180^{\circ} \mathrm{C}\right)$. During the frying, the water in the food evaporates and is transferred to the oil, where simultaneously the food absorbs oil to partly replace the water removed from the product $[5,6]$. In the frying process, the thermal and physicochemical properties of the food and oil, the geometry of the food and the temperature of the oil, are some of the variables that affect the transfer of mass and heat, and that ultimately determine the characteristics of the fried products $[7,8]$. During the frying is modified the sample microstructure, the organoleptic characteristics because of Maillard's rection, and there is a reduction of water activity which promotes the conservation of food $[9,10]$.

The inconvenient of fried products is the high-fat content because of oil absorption during the frying process. Therefore, this process can be accompanied by pretreatments, such as osmotic dehydration (OD), which by decreasing the initial moisture content can decrease the oil content in the final product, as well as improve its texture and flavour [11]. Osmotic dehydration is a low-cost technology since it is a non-thermal process, in which raw materials are immersed in a hypertonic solution composed of solutes capable of generating high pressures [12]. The usefulness of OD treatments not only was demonstrated for frying but also as pre-treatment for further drying of bananas slices [13]. With osmotic dehydration, the quality and stability of fruit and vegetable products can be preserved by reducing the moisture content (up to 50-60\%) and increasing the soluble solids content [14].

Different mathematical models (empirical and semiempirical, mechanistic, and phenomenological) have been proposed to describe or predict the mass transfer kinetics of the OD process. The mass transfer during OD process may be evaluated by the water loss (WL) and solids gain (SG), which can be calculated by the following (1) and (2), respectively [15].

$1^{\text {th }}$ LACCEI International Multi-Conference for Engineering, Education, and Technology: "Engineering, Integration, and Alliances for a Sustainable Development" "Hemispheric Cooperation for Competitiveness and Prosperity on a Knowledge-Based Economy", 27-31 July 2020, Virtual Edition. 
$W L=\frac{\left(m_{0} \cdot X_{w 0}-m_{t} \cdot X_{w t}\right)}{m_{0}}$

$S G=\frac{\left(m_{0} \cdot X_{S 0}-m_{t} \cdot X_{S t}\right)}{m_{0}}$

Where $m_{0}$ and $m_{t}$ are the initial sample mass and after a certain OD time $(\mathrm{t})$, respectively; $X_{w 0}$ and $X_{w t}$ are their water fractions; $X_{S 0}$ and $X_{S t}$ are their solid fractions.

Therefore, this study aimed to describe the OD mass transfer through the water loss and solid gain kinetics during OD of banana slices using different solutes and concentration. In addition, the influence of OD treatments in fat content and sensorial attributes were evaluated in the fried product (banana chips).

\section{MATERIAL AND METHODS}

\section{A. Raw material and osmotic dehydration (OD)} treatments

Fresh bananas (Musa balbisiana) were obtained from "La Hermelinda" market, Trujillo, Peru. They were washed, peeled, and subsequently sliced $(1.5 \pm 0.5 \mathrm{~mm}$ thickness). The banana slices were treated without (Control samples) and with osmotic solutions by immersion at room temperature. The osmotic dehydration treatment included the use of two osmotic solutions, one prepared with sucrose at 60 ${ }^{\circ}$ Brix (hereinafter called Sucrose OD treatment) and the other prepared with a combination of salt $(1.5 \% \mathrm{~m} / \mathrm{m})$ and sucrose (45 ${ }^{\circ}$ Brix) (hereinafter called Salt + Sucrose OD treatment).

For each treatment, it was used 49 banana slices independently distributed in each osmotic solution $(14 \mathrm{~mL}$ of OD solution/g of sample). The weight and moisture of samples were evaluated along $24 \mathrm{~h}$ of osmotic dehydration at time intervals of 5, 10, 15, 30, 60 and $90 \mathrm{~min}$. At each time, the samples were taken from osmotic solution, superficially dried and weighed. The moisture was determined before and after OD by drying at $105{ }^{\circ} \mathrm{C}$ for $3 \mathrm{~h}$. The treatments were carried out in triplicate.

\section{B. Kinetics modelling of WL and SG during osmotic dehydration}

Empirical and semi-empirical models were used to describe the WL and SG during OD. It was used these types of models since these are of broader application in OD, and some allowed not only to obtain kinetics parameters but also parameters related to the equilibrium mass transfer [15]. The Azuara's Model [16] (3) and (4), Peleg's Model [17] (5) and (6), Page's Model [18] (7) and (8), Weibull's Model [19, 20] (9) and (10), and the First-Order model (also called Newton or Lewis model) [21] (11) and (12) were used. All equations were write considering that the initial (OD time $=0$ ) WL and $\mathrm{SG}$ are equal to zero.

$W L=\frac{s_{1} \cdot t \cdot W L_{\infty}}{1+s_{1} \cdot t}$

$S G=\frac{s_{2} \cdot t \cdot S G_{\infty}}{1+s_{2} \cdot t}$

$s_{1}$ and $s_{2}$ are the WL and SG coefficients, $W L_{\infty}$ and $S G_{\infty}$ are the equilibrium point of WL and SG.

$W L=\frac{t}{k_{1}^{W}+k_{2}^{W} \cdot t}$

$S G=\frac{t}{k_{1}^{S}+k_{2}^{S} \cdot t}$

The $k_{1}^{w}\left(\mathrm{WL}^{-1} \cdot \mathrm{min}\right)$ and $k_{1}^{s}\left(\mathrm{SG}^{-1} \cdot \mathrm{min}\right)$ reciprocal are related to the initial WL and $\mathrm{SG}$ rate, respectively. The $k_{1}^{w}$ $\left(\mathrm{WL}^{-1}\right)$ and $k_{1}^{s}\left(\mathrm{SG}^{-1}\right)$ reciprocal are related to the $\mathrm{WL}$ and $\mathrm{SG}$ equilibrium when $\mathrm{t} \rightarrow \infty$.

$W L=W L_{\infty}-W L_{\infty} \cdot e^{-k_{w} \cdot t^{n_{W}}}$

$S G=S G_{\infty}-S G_{\infty} \cdot e^{-k_{s} \cdot t^{n_{S}}}$

Where $W L_{\infty}$ and $S G_{\infty}$ are the WL and SG at the equilibrium when $\mathrm{t} \rightarrow \infty . k_{w}$ and $k_{s}$ are the kinetics parameter related to initial WL and SG rate. $n_{w}$ and $n_{s}$ are the page's parameters for WL and SG, which could be associated with the type of mass transfer mechanisms [22, 23].

$W L=W L_{\infty}-W L_{\infty} \cdot e^{-\left(\frac{t}{\alpha_{w}}\right)^{\beta_{W}}}$

$S G=S G_{\infty}-S G_{\infty} \cdot e^{-\left(\frac{t}{\alpha_{S}}\right)^{\beta_{S}}}$

$\alpha \mathrm{W}$ and $\alpha$ s are associated with the WL and SG rate and represent the time required for $\frac{W L}{W L}$ and $\frac{S G}{S G}$ to reach the value of (1-e-1). $\beta_{w}$ and $\beta_{s}$ in both cases indicate the convex shape $(\beta<1)$ of the WL and SG curves.

$W L=W L_{\infty}-W L_{\infty} \cdot e^{-k_{w} \cdot t}$
$S G=S G_{\infty}-S G_{\infty} \cdot e^{-k_{s} \cdot t}$

Where $W L_{\infty}$ and $S G_{\infty}$ are the WL and SG at the equilibrium when $\mathrm{t} \rightarrow \infty$. $k_{w}$ and $k_{s}$ are the WL and SG kinetics parameter.

The models were fitted to experimental data by identifying their parameter values that minimize the sum of squared errors (SSE, Eq.13) between the experimental and the predicted values. The Generalized Reduced Gradient method implemented in the 'Solver' tool of software Excel 2016 (Microsoft, USA) was used for this purpose.

$\mathrm{SSE}=\sum_{\mathrm{i}=1}^{\mathrm{x}}((\text { predicted })-(\text { experimental }))_{\mathrm{i}}^{2}$

To report the fit criteria of the models were considered: the minimized SSE, the coefficient of determination $\left(\mathrm{R}^{2}\right)$, the root-mean-square deviation values (RMSD) (14), and by plotting the values obtained by the model (predicted) as a function of the experimental values. The regression of those data to a linear function (15) results in two parameters that can also be used to evaluate the model 
adjustment, i.e. the linear slope (a; that must be as close as possible to the unit) and the intercept (b; that must be as close as possible to zero).

$$
\begin{aligned}
& R M S D=\sqrt{\frac{S S E}{n}} \\
& \text { predicted }=a \cdot \text { experimental }+b
\end{aligned}
$$

\section{C. $\quad$ Fat content determination}

After the OD process, the samples were fried by immersion in vegetable oil at $180{ }^{\circ} \mathrm{C}$ for $2 \mathrm{~min}$. After frying, the fat content (\%) in banana chips was determined using the continuous Soxhlet extraction method [24]. After frying the samples were dried, triturated and placed inside a thick filter paper thimble, which was placed into the Soxhlet equipment for oil extraction. The determination was performed in triplicate for each treatment.

$\%$ fat content $=\left(\frac{m_{f}}{m_{s}}\right) .100$

Where $m_{f}$ and $m_{s}$ represents the fat and the sample weight, respectively

\section{Instrumental colour measurement}

The colour was measured after frying for the different treatments including the control samples using a colourimeter (CM-5, Konica Minolta, Japan). The CIE (Commission Internationale d'Eclairage) colour scale was used, where parameters of $\mathrm{L}^{*}$ indicates the luminosity of the samples, $\mathrm{a}^{*}$ indicates the tendency in reddish or brown colour in the samples and $b^{*}$ indicates the tendency to have a yellow or golden colour.

\section{E. Sensorial evaluation}

After frying, the sensory attributes evaluated were flavour, colour and texture using a 9-point hedonic scale from dislike extremely (1) to like extremely (9). A total of 30 consumers participated in the evaluation. After receiving instructions, the samples were presented to consumers using a monadic sequential design.

\section{F. $\quad$ Statistical analyses}

All processes and analyses were performed at least 3 times. The one-way ANOVA was carried out with a significance level of 5\%. To determine statistical differences among means of treatments, Tukey test was used. Statistical analyses were determined using the IBM SPSS Statistics 23 software (IBM SPSS, USA).

\section{RESULTS AND DISCUSSION}

\section{A. $\quad$ Water loss (WL) and solids gain (SG) kinetics during} osmotic dehydration

It was observed that when the sucrose solution was used, the water content of raw sample was reduced by $31 \%$ after 120 min of osmotic dehydration. In the case of using the Salt + Sucrose solution, there was a $25 \%$ water content reduction. Similar results were obtained by Nowakunda, et al. [13], where at higher concentrations of sucrose (65 $\left.{ }^{\circ} \mathrm{Brix}\right)$ caused about $50 \%$ of water loss at times less than 120 minutes. In the case of solids content, it increased $10 \%$ after 120 min of OD when sucrose solution was used (Figure1.B), on contrary when salt + sucrose solution was used, it increased 5\% after the same OD time (Figure2.B).

Therefore, under the studied conditions, when was used sucrose solution (Fig. 1), the mass transfer was greater than when was used salt + sucrose solution (Fig. 2). Since, at higher osmotic solution concentration, the higher solid incorporation [25]. The results could be explained by the low salt and sucrose concentrations used. Mercali, et al. [26] reported that when was used $10 \%$ of salt with $30 \%$ of sucrose, it was obtained the best water transport from the banana samples. It corroborates that the solute type and concentration can influence the mass transfer during the osmotic dehydration process.
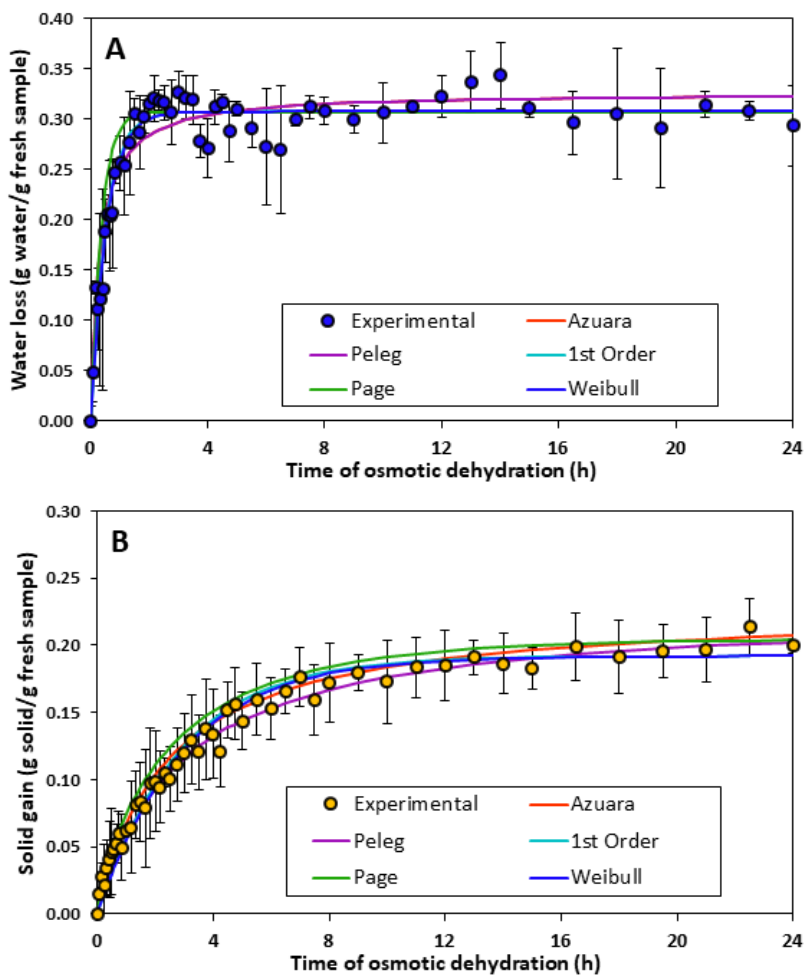

Fig. 1. Water loss (A) and solid gain (B) during $24 \mathrm{~h}$ of banana osmotic dehydration using sucrose $\left(60^{\circ} \mathrm{Brix}\right)$ solution. Dots are the experimental data and continuous curves are the modelled data.

On the other hand, as observed in Figures 1.A and 2.A, the greater water loss was achieved in the first 2 hours, and after 4 hours the curves reached an asymptotic behaviour, which means that after this time, the samples will no longer lose a significant amount of water. Therefore, it may not be necessary longer hours of OD. This agreed with Nowakunda, et al. [13] who performed OD process in banana samples under similar conditions $\left(30^{\circ} \mathrm{C}\right.$, sucrose 55 or $\left.65^{\circ} \mathrm{Brix}\right)$ and 
observed that the most efficient water removal occurs in the first 2 hours. On the contrary, the solid gain behaviour (Fig. 1.B and 2.b) indicates that it occurs in a minor rate and for a longer time if compared to water loss. It could be related to the fact that during OD mass transfer, the water outflow from inside food matrix occurs firstly and more quickly than the solute transfer into the food matrix [27].
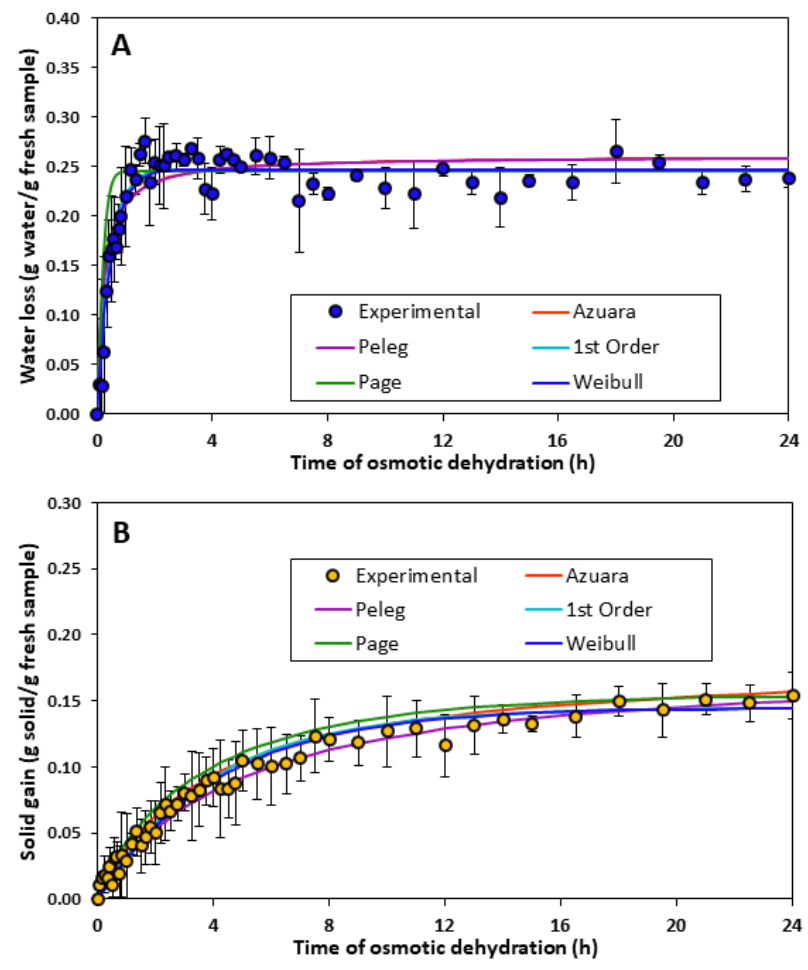

Fig. 2. Water loss (A) and solids gain (B) during $24 \mathrm{~h}$ osmotic dehydration using salt $(1.5 \% \mathrm{~m} / \mathrm{m})+$ sucrose $\left(45^{\circ}\right.$ Brix $)$ solution. Dots are the experimental data and continuous curves are the modelled data.

The water loss and solid gain during osmotic dehydration were well described by using five mathematical models, which calculated data were presented in Figures 1 and 2, while their parameters and fit criteria were presented in Tables I and II. By comparing the fit criteria (Table I), the mathematical models presented a better fit for the solid gain data ( $>\mathrm{R}^{2},<\mathrm{RMSE}, \mathrm{b} \sim 0$ and $\mathrm{a} \sim 1$ ) (Table I). By comparing the type of OD solution, apparently for WL, the models fit better for sucrose solution, while in SG, these fit better for Salt + Sucrose solution.

The model's parameters reflected the WL and SG behaviour in Figures 1 and 2. Except for Peleg parameters, the parameters obtained for WL were higher than SG parameters reflecting that the WL occurs more quickly and the amount of water loss is higher than the amount of solid gain. The same was reported by Farhaninejad, et al. [28], where the Peleg parameters are higher for the SG than WL Peleg parameters. In the case of OD with only sucrose, the values of $W L_{\infty}$ and $S G_{\infty}$, from all models were higher; the $k_{2}^{w}, k_{2}^{s}$ from Peleg Model were lower than those obtained for OD with salt + sucrose solution. It means that effectively, the amount of water loss, and solids gain are higher when using a high concentration osmotic solution such as sucrose at 60 ${ }^{\circ}$ brix. On the contrary, the kinetic parameters from all models did not show significant statistic differences $(p>0.05)$. That is, probably in both OD employed solutions, the rate initial rate of WL and SG was similar.

\section{B. Characteristics of fried banana chips}

\section{Fat content}

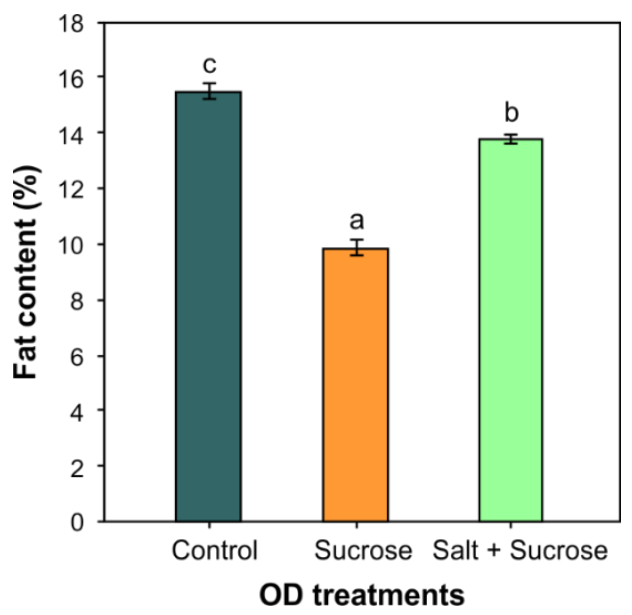

Fig. 3. Fat content in fried samples after each OD treatment. Different letters showed significant differences $(p<0.05)$ among OD treatments.

During frying, there is oil uptake increasing the banana chips fat content [4]. Fig. 3 shows the fat content (\%) of fried banana samples. The Control samples presented a fat content of $15.5 \pm 0.3 \%$, which was in the range reported by Elkhalifa, et al. [4], Wani, et al. [29] in fried banana chips. The main process parameters influencing oil uptake are frying temperature, drying time, thickness, among others [30, 31]. Since all these variables were maintained constant, the observed fat content reduction could be attributed to OD treatments effect. Both OD treatments reduced the fat content in more than $11 \%$. However, the OD with sucrose allowed to obtain fried samples with the lowest fat content. Lower fat content was also reported in banana chips as the sucrose concentration used for the treatment was increased [32]. During the frying process, simultaneously to water vaporization from inside the food matrix, there is oil intake. Therefore, there was a correlation between the moisture after OD and the amount of oil absorbed, where at low moisture (high WL), low-fat content (\%). It makes sense since effectively, the treatment that presented high WL (Sucrose OD treatment), presented the lowest fat content. Similar behaviour was observed by Diaz, et al. [33] in fried banana samples after OD. Other treatments were performed to decrease oil absorption during the frying process of banana chips. For example, it was also applied pre-treatments with hydrocolloids [34]. 
TABLE I

MATHEMATICAL MODEL PARAMETERS AND FIT CRITERIA FOR THE WATER LOSS DURING OSMOTIC DEHYDRATION. DIFFERENT SUPERSCRIPT LETTERS IN THE PARAMETER VALUE FOR EACH MODEL, INDICATE SIGNIFICANT DIFFERENCES (P<0.05) BETWEEN SUCROSE AND SALT + SUCROSE OD TREATMENTS.

\begin{tabular}{|c|c|c|c|c|}
\hline \multirow{2}{*}{ Models } & \multicolumn{2}{|c|}{ Water loss (Sucrose $60^{\circ}$ Brix) } & \multicolumn{2}{|c|}{ Water loss (Salt $(1.5 \% \mathrm{w} / \mathrm{w})+$ Sucrose $\left(45^{\circ}\right.$ Brix $\left.)\right)$} \\
\hline & Model parameters & Model accuracy & Model parameters & Model accuracy \\
\hline Azuara & $\begin{array}{l}s_{1}=0.056 \pm 0.025^{\mathrm{c}} \\
W L_{\infty}=0.326 \pm 0.012^{\mathrm{c}}\end{array}$ & $\begin{array}{l}\text { RMSE }=0.277 \pm 0.009 \\
\mathrm{a}=1.036 \pm 0.019 \\
\mathrm{~b}=-0.01 \pm 0.005 \\
\mathrm{R}^{2} \geq 0.758\end{array}$ & $\begin{array}{l}s_{1}=0.073 \pm 0.045^{\mathrm{c}} \\
W L_{\infty}=0.261 \pm 0.006^{\mathrm{d}}\end{array}$ & $\begin{array}{l}\text { RMSE }=0.225 \pm 0.01 \\
\mathrm{a}=1.092 \pm 0.091 \\
\mathrm{~b}=-0.021 \pm 0.02 \\
\mathrm{R}^{2} \geq 0.709\end{array}$ \\
\hline Peleg & $\begin{array}{l}k_{1}^{w}=65.049 \pm 34.33^{c} \\
k_{2}^{w}=3.067 \pm 0.115^{c}\end{array}$ & $\begin{array}{l}\text { RMSE }=0.277 \pm 0.009 \\
\mathrm{a}=1.036 \pm 0.019 \\
\mathrm{~b}=-0.01 \pm 0.005 \\
\mathrm{R}^{2} \geq 0.758\end{array}$ & $\begin{array}{l}k_{1}^{w}=71.817 \pm 49.711^{\mathrm{c}} \\
k_{2}^{w}=3.836 \pm 0.082^{\mathrm{d}}\end{array}$ & $\begin{array}{l}\text { RMSE }=0.225 \pm 0.01 \\
\mathrm{a}=1.092 \pm 0.091 \\
\mathrm{~b}=-0.021 \pm 0.02 \\
\mathrm{R}^{2} \geq 0.709\end{array}$ \\
\hline Weibull & $\begin{array}{l}W L_{\infty}=0.307 \pm 0.008^{\mathrm{d}} \\
\alpha_{w}=7.151 \pm 1.272^{\mathrm{c}} \\
\beta_{w}=0.223 \pm 0.049^{\mathrm{c}}\end{array}$ & $\begin{array}{l}\text { RMSE }=0.278 \pm 0.008 \\
\mathrm{a}=0.987 \pm 0.053 \\
\mathrm{~b}=0.004 \pm 0.015 \\
\mathrm{R}^{2} \geq 0.804\end{array}$ & $\begin{array}{l}W L_{\infty}=0.247 \pm 0.002^{\mathrm{c}} \\
\alpha_{w}=6.323 \pm 1.803^{\mathrm{c}} \\
\beta_{w}=0.222 \pm 0.042^{\mathrm{c}}\end{array}$ & $\begin{array}{l}\text { RMSE }=0.226 \pm 0.01 \\
a=1.074 \pm 0.167 \\
b=-0.017 \pm 0.038 \\
R^{2} \geq 0.786\end{array}$ \\
\hline Page & $\begin{array}{l}W L_{\infty}=0.307 \pm 0.007^{\mathrm{d}} \\
k_{w}=0.038 \pm 0.031^{\mathrm{c}} \\
n_{w}=1.054 \pm 0.265^{\mathrm{c}}\end{array}$ & $\begin{array}{l}\text { RMSE }=0.278 \pm 0.008 \\
\mathrm{a}=0.98 \pm 0.012 \\
\mathrm{~b}=0.006 \pm 0.003 \\
\mathrm{R}^{2} \geq 0.816\end{array}$ & $\begin{array}{l}W L_{\infty}=0.246 \pm 0.004^{\mathrm{c}} \\
k_{w}=0.032 \pm 0.029^{\mathrm{c}} \\
n_{w}=1.309 \pm 0.553^{\mathrm{c}}\end{array}$ & $\begin{array}{l}\text { RMSE }=0.226 \pm 0.009 \\
\mathrm{a}=1.03 \pm 0.085 \\
\mathrm{~b}=-0.007 \pm 0.02 \\
\mathrm{R}^{2} \geq 0.786\end{array}$ \\
\hline $1^{\text {st }}$ Order & $\begin{array}{l}W L_{\infty}=0.307 \pm 0.008^{\mathrm{d}} \\
k_{w}=0.033 \pm 0.012^{\mathrm{c}}\end{array}$ & $\begin{array}{l}\text { RMSE }=0.278 \pm 0.008 \\
\mathrm{a}=0.987 \pm 0.053 \\
\mathrm{~b}=0.004 \pm 0.015 \\
\mathrm{R}^{2} \geq 0.804\end{array}$ & $\begin{array}{l}W L_{\infty}=0.247 \pm 0.002^{\mathrm{c}} \\
k_{w}=0.038 \pm 0.016^{\mathrm{c}}\end{array}$ & $\begin{array}{l}\text { RMSE }=0.226 \pm 0.01 \\
\mathrm{a}=1.074 \pm 0.167 \\
\mathrm{~b}=-0.017 \pm 0.038 \\
\mathrm{R}^{2} \geq 0.786\end{array}$ \\
\hline
\end{tabular}

TABLE II

MATHEMATICAL MODEL PARAMETERS AND FIT CRITERIA FOR THE SOLID GAIN DURING OSMOTIC DEHYDRATION. DIFFERENT SUPERSCRIPT LETTERS IN THE PARAMETER VALUE FOR EACH MODEL, INDICATE SIGNIFICANT DIFFERENCES (P<0.05) BETWEEN SUCROSE AND SALT + SUCROSE OD TREATMENTS.

\begin{tabular}{|c|c|c|c|c|}
\hline \multirow{2}{*}{ Models } & \multicolumn{2}{|c|}{ Solid gain (Sucrose $60^{\circ}$ Brix) } & \multicolumn{2}{|c|}{ Solid gain (Salt $(1.5 \% \mathrm{w} / \mathrm{w})+$ Sucrose $\left(45^{\circ}\right.$ Brix $\left.)\right)$} \\
\hline & \begin{tabular}{|l|} 
Model parameters \\
\end{tabular} & Model accuracy & Model parameters & Model accuracy \\
\hline Azuara & $\begin{array}{l}s_{2}=0.007 \pm 0.003^{\mathrm{c}} \\
S G_{\infty}=0.228 \pm 0.018^{\mathrm{d}}\end{array}$ & $\begin{array}{l}\text { RMSE }=0.135 \pm 0.018 \\
a=0.98 \pm 0.034 \\
b=0.003 \pm 0.006 \\
R^{2} \geq 0.947\end{array}$ & $\begin{array}{l}S_{2}=0.005 \pm 0.003^{\mathrm{c}} \\
S G_{\infty}=0.181 \pm 0.017^{\mathrm{c}}\end{array}$ & $\begin{array}{l}\text { RMSE }=0.092 \pm 0.016 \\
a=0.987 \pm 0.015 \\
b=0.001 \pm 0.002 \\
\mathrm{R}^{2} \geq 0.947\end{array}$ \\
\hline Peleg & $\begin{array}{l}k_{1}^{s}=759.966 \pm 425.01^{\mathrm{c}} \\
k_{2}^{s}=4.408 \pm 0.374^{\mathrm{c}}\end{array}$ & $\begin{array}{l}\text { RMSE }=0.135 \pm 0.018 \\
\mathrm{a}=0.98 \pm 0.034 \\
\mathrm{~b}=0.003 \pm 0.006 \\
\mathrm{R}^{2} \geq 0.947\end{array}$ & $\begin{array}{l}k_{1}^{S}=1589.229 \pm 930.956^{\mathrm{c}} \\
k_{2}^{s}=5.555 \pm 0.507^{\mathrm{d}}\end{array}$ & $\begin{array}{l}\text { RMSE }=0.092 \pm 0.016 \\
\mathrm{a}=0.987 \pm 0.015 \\
\mathrm{~b}=0.001 \pm 0.002 \\
\mathrm{R}^{2} \geq 0.947\end{array}$ \\
\hline Weibull & $\begin{array}{l}S G_{\infty}=0.192 \pm 0.015^{\mathrm{d}} \\
\alpha_{S}=13.09 \pm 2.046^{\mathrm{c}} \\
\beta_{S}=0.074 \pm 0.018^{\mathrm{c}}\end{array}$ & $\begin{array}{l}\text { RMSE }=0.135 \pm 0.018 \\
\mathrm{a}=0.933 \pm 0.052 \\
\mathrm{~b}=0.011 \pm 0.009 \\
\mathrm{R}^{2} \geq 0.940\end{array}$ & $\begin{array}{l}S G_{\infty}=0.145 \pm 0.008^{\mathrm{c}} \\
\alpha_{S}=14.589 \pm 2.222^{\mathrm{c}} \\
\beta_{S}=0.059 \pm 0.02^{\mathrm{c}}\end{array}$ & $\begin{array}{l}\text { RMSE }=0.092 \pm 0.016 \\
\mathrm{a}=0.954 \pm 0.03 \\
\mathrm{~b}=0.005 \pm 0.004 \\
\mathrm{R}^{2} \geq 0.947\end{array}$ \\
\hline Page & $\begin{array}{l}S G_{\infty}=0.205 \pm 0.024^{\mathrm{d}} \\
k_{S}=0.019 \pm 0.013^{\mathrm{c}} \\
n_{s}=0.777 \pm 0.125^{\mathrm{c}}\end{array}$ & $\begin{array}{l}\text { RMSE }=0.135 \pm 0.019 \\
\mathrm{a}=0.996 \pm 0.01 \\
\mathrm{~b}=0.001 \pm 0.002 \\
\mathrm{R}^{2} \geq 0.947\end{array}$ & $\begin{array}{l}S G_{\infty}=0.155 \pm 0.013^{\mathrm{c}} \\
k_{S}=0.011 \pm 0.01^{\mathrm{c}} \\
n_{S}=0.824 \pm 0.102^{\mathrm{c}}\end{array}$ & $\begin{array}{l}\text { RMSE }=0.092 \pm 0.016 \\
\mathrm{a}=0.998 \pm 0.007 \\
\mathrm{~b}=0 \pm 0.001 \\
\mathrm{R}^{2} \geq 0.947\end{array}$ \\
\hline $1^{\text {st }}$ Order & $\begin{array}{l}S G_{\infty}=0.192 \pm 0.015^{\mathrm{d}} \\
k_{S}=0.006 \pm 0.002^{\mathrm{c}}\end{array}$ & $\begin{array}{l}\text { RMSE }=0.135 \pm 0.018 \\
\mathrm{a}=0.933 \pm 0.052 \\
\mathrm{~b}=0.011 \pm 0.009 \\
\mathrm{R}^{2} \geq 0.940\end{array}$ & $\begin{array}{l}S G_{\infty}=0.145 \pm 0.008^{\mathrm{c}} \\
k_{S}=0.004 \pm 0.002^{\mathrm{c}}\end{array}$ & $\begin{array}{l}\text { RMSE }=0.092 \pm 0.016 \\
\mathrm{a}=0.954 \pm 0.03 \\
\mathrm{~b}=0.005 \pm 0.004 \\
\mathrm{R}^{2} \geq 0.947\end{array}$ \\
\hline
\end{tabular}

18 $^{\text {th }}$ LACCEI International Multi-Conference for Engineering, Education, and Technology: "Engineering, Integration, and Alliances for a Sustainable Development" "Hemispheric Cooperation for Competitiveness and Prosperity on a Knowledge-Based Economy", 29-31 July 2020, Buenos Aires, Argentina. 5 
A

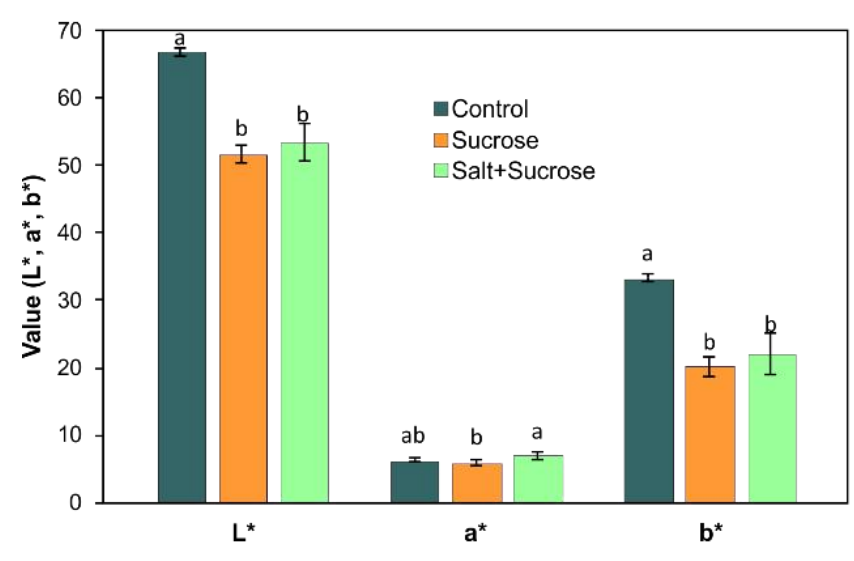

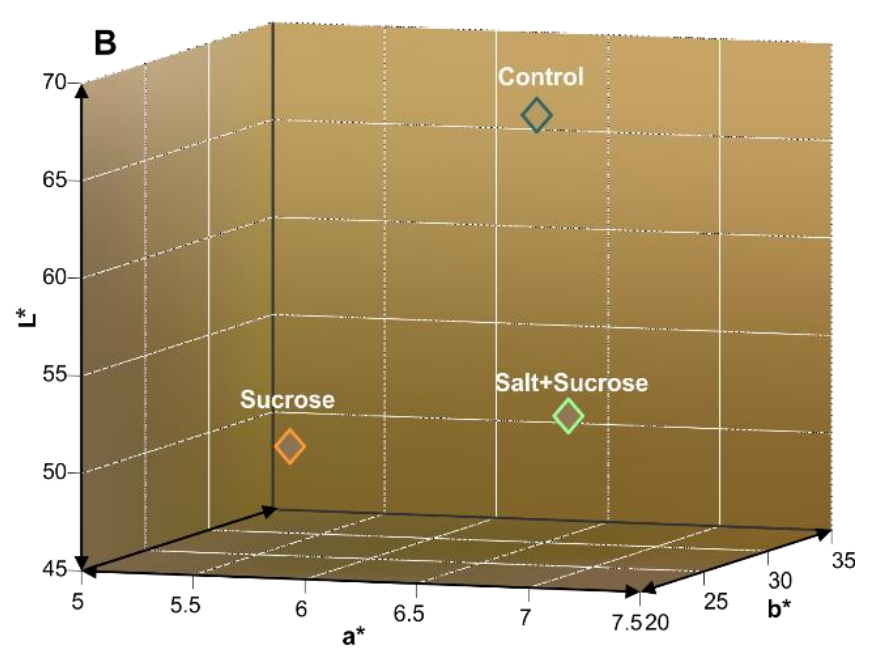

Fig. 4. $\mathrm{L}^{*} \mathrm{a} * \mathrm{~b} *$ parameters value, different letters indicate significant differences $(\mathrm{p}<0.05)$ among OD treatments $(\mathrm{A})$. Spatial disposition of fried samples represented in a $3 \mathrm{D}$ plot of instrumental colour parameters $\mathrm{L} * \mathrm{a} * \mathrm{~b} *(B)$.

The OD treatments and frying, significantly affected the banana chips colour parameters, as expressed in Fig. 4. Thus, compared to Control, the luminosity $\left(\mathrm{L}^{*}\right)$ values were significantly lower $(\mathrm{p}<0.05)$ in samples with OD treatments. Reductions in $\mathrm{L}^{*}$ were also observed in samples that was treated with OD [35]. The $\mathrm{L}^{*}$ value is correlated with the brightness level of the samples and it could be influenced by the surface properties and composition modifications produced by OD. Regarding the $\mathrm{a}^{*}$ parameter, no significant changes $(p<0.05)$ were observed in osmotically dehydrated samples regarding the Control. However, there were differences between both OD treatments where an increase in $a^{*}$ was obtained in samples with salt + sucrose OD treatment. The increase of $b^{*}$ parameter means a tendency to yellow colour; therefore, the OD samples showed less yellowness.

The spatial arrangement of the samples in a 3D graph $\left(\mathrm{L}^{*}, \mathrm{a}^{*}, \mathrm{~b}^{*}\right)$ is shown in Fig. 4.B. Regarding the Control samples, the OD application decreased the $\mathrm{L}^{*}$, increased the $a^{*}$ in the case of Sal + Sucrose solution, and decreased the $b^{*}$ value. At higher concentration of osmotic dehydration solutions, higher colour differences were observed [28]. These differences could be explained by the sample structure and composition modifications because of OD but also during frying [29].

\section{Sensorial evaluation}

The colour, flavour and texture attributes were evaluated (Fig. 5). By analysing the colour attribute, compared to Control, the consumers showed more acceptance for OD samples. It could be explained by the golden appearance of these samples. Regarding flavour, the consumers preferred the samples treated with OD using sucrose, probably the sweet taste is influenced positively in the acceptance of these samples. The texture of the Control samples showed the best score compared to the texture of samples with OD. During osmotic dehydration in addition to mass transfer, it occurs structural modifications which probably impacted negatively in the texture attribute of banana chips.

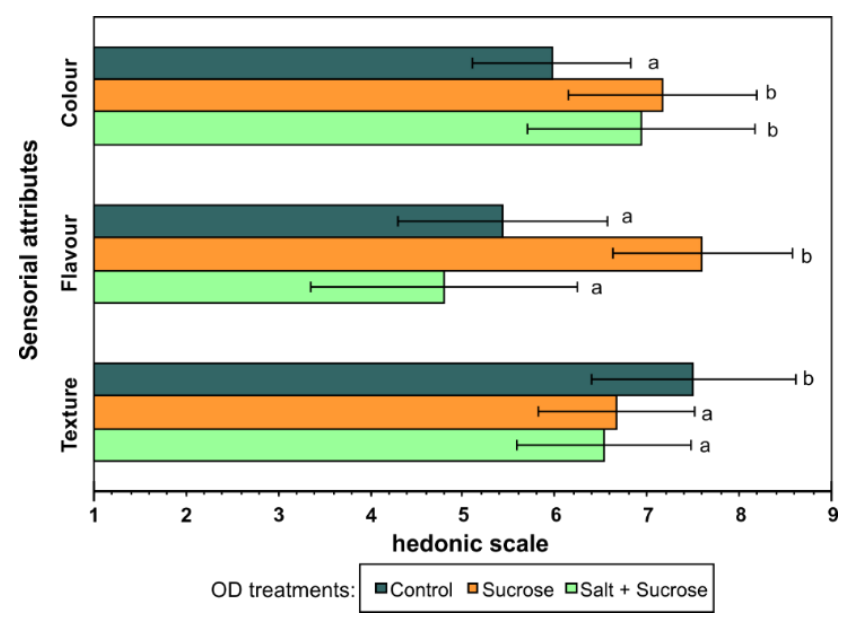

Fig. 5. Sensorial attributes evaluation in fried samples after each OD treatment. Different letters showed significant differences $(\mathrm{p}<0.05)$ among OD treatments for each sensorial attribute.

\section{CONCLUSIONS}

The behaviour of water loss and solids gain over time was described by using different mathematical models whose parameters showed that the water loss and solid gain increased when it was used sucrose solution $\left(60^{\circ}\right.$ Brix $)$ during osmotic dehydration (OD). Therefore, this solution had a better dehydrating effect on the banana slices. From mathematical models used, all showed good fit, however, a better fit of these models to the solid gain data $\left(>\mathrm{R}^{2},<\right.$ RMSE, $\mathrm{b} \sim 0$ and $\mathrm{a} \sim 1$ ) was observed. It was interesting to note that most of the water loss occurred within the first 2 
hours, and it occurs faster and in higher amounts than solid gain. The OD decreases the water content in banana slices; therefore, the oil intake decreases during frying, thus reducing the fat content in more than $11 \%$. The banana chips mainly decreased their luminosity and decreased the $b^{*}$ value after osmotic dehydration and after the frying process. Furthermore, compared to Control, the sensorial attributes most preferred in samples with OD was the colour and the flavour of samples with Sucrose OD solution.

\section{REFERENCES}

[1] FAO. Banana facts and figures [Online]. Available: http://www.fao.org/economic/est/est-

commodities/bananas/bananafacts/en/\#.XlrtVahKjIU

[2] D. V. Miranda, M. L. Rojas, S. Pagador, L. Lescano, J. SanchezGonzalez, and G. Linares, "Gluten-Free Snacks Based on Brown Rice and Amaranth Flour with Incorporation of Cactus Pear Peel Powder: Physical, Nutritional, and Sensorial Properties," International Journal of Food Science, vol. 2018, p. 9, 2018.

[3] A. L. Gabas, J. Telis-Romero, G. I. Giraldo-Gómez, and V. R. N Telis, "Propiedades termodinámicas de sorción de agua de la pulpa de lulo en polvo con encapsulantes," Food Science and Technology, vol. 29, pp. 911-918, 2009.

[4] A. E. O. Elkhalifa, A. M. Hassan, and M. E. A. Zei, "Analytical quality and acceptability of baked and fried banana chips," Journal of Human Nutrition and Food Science, vol. 2, p. 1052, 2014.

[5] M. Mellema, "Mechanism and reduction of fat uptake in deep-fat fried foods," Trends in Food Science \& Technology, vol. 14, pp. 364-373, 2003/09/01/ 2003

[6] G. Cruz, J. P. Cruz-Tirado, K. Delgado, Y. Guzman, F. Castro, M. L. Rojas, et al., "Impact of pre-drying and frying time on physical properties and sensorial acceptability of fried potato chips," Journal of Food Science and Technology, vol. 55, pp. 138-144, 2018/01/01 2018.

[7] F. Pedreschi and P. Moyano, "Oil uptake and texture development in fried potato slices," Journal of Food Engineering, vol. 70, pp. 557-563, 10// 2005.

[8] F. Pedreschi and P. Moyano, "Effect of pre-drying on texture and oil uptake of potato chips," LWT-Food Science and technology, vol. 38, pp. 599-604, 2005.

[9] P. Bouchon and J. M. Aguilera, "Microstructural analysis of frying potatoes," International journal of food science \& technology, vol. 36, pp. 669-676, 2001.

[10] N. Achir, O. Vitrac, and G. Trystram, "Simulation and ability to control the surface thermal history and reactions during deep fat frying," Chemical Engineering and Processing: Process Intensification, vol. 47, pp. 1953-1967, 2008.

[11] J. Ikoko and V. Kuri, "Osmotic pre-treatment effect on fat intake reduction and eating quality of deep-fried plantain," Food Chemistry, vol. 102, pp. 523-531, 2007.

[12] L. Torres and P. TABARQUINO, "Deshidratación Osmótica de plátano (Musa paradisiaca L Var. Dominico Hartón) como pretratamiento a la fritura [Tesis Ingeniería Agrícola]," Cali (Colombia): Universidad del Valle, Facultad de Ingeniería, 2007.

[13] K. Nowakunda, A. Andrés, and P. Fito, "Osmotic dehydration of banana slices as a pretreatment for drying processes," in The international drying symposium, 2004, pp. 2077-2083.

[14] G. V. Barbosa-Cánovas and H. Vega-Mercado, Deshidratación de alimentos, 2000.

[15] F. R. Assis, R. M. Morais, and A. M. Morais, "Mass transfer in osmotic dehydration of food products: comparison between mathematical models," Food engineering reviews, vol. 8, pp. 116-133, 2016.
[16] E. Azuara, R. Cortés, H. S. Garcia, and C. I. Beristain, "Kinetic model for osmotic dehydration and its relationship with Fick's second law," International journal of food science \& technology, vol. 27, pp. 409-418, 1992.

[17] M. Peleg, "Characterization of the stress relaxation curves of solid foods," Journal of Food Science, vol. 44, pp. 277-281, 1979.

[18] G. E. Page, "Factors Influencing the Maximum Rates of Air Drying Shelled Corn in Thin layers," Purdue University, Ann Arbor, 1949.

[19] W. Weibull, "A Statistical Distribution Function of Wide Applicability," Journal of applied mechanics, vol. 103, pp. 293297, 1951.

[20] R. L. Smith, "Weibull regression models for reliability data," Reliability Engineering \& System Safety, vol. 34, pp. 55-76, 1991/01/01 1991.

[21] N. Panagiotou, V. Karathanos, and Z. Maroulis, "Effect of osmotic agent on osmotic dehydration of fruits," Drying Technology, vol. 17, pp. 175-189, 1999

[22] R. Simpson, C. Ramírez, H. Nuñez, A. Jaques, and S. Almonacid, "Understanding the success of Page's model and related empirical equations in fitting experimental data of diffusion phenomena in food matrices," Trends in Food Science \& Technology, vol. 62, pp. 194-201, 2017.

[23] M. L. Rojas and P. E. D. Augusto, "Microstructure elements affect the mass transfer in foods: The case of convective drying and rehydration of pumpkin," LWT, vol. 93, pp. 102-108, 7/I 2018.

[24] AOAC, Official methods of analysis, 15 ed. Virginia: Arlington: ASSOTIATION OF OFFICIAL ANALYTICAL CHEMIST, INC., 1990.

[25] M. Castillo and F. Cornejo, "Estudio del efecto del proceso de deshidratación osmótica en la obtención de trozos secos de carambola (Averroha carambola L.)," Revista TecnológicaESPOL, vol. 20, 2007.

[26] G. D. Mercali, L. D. Ferreira Marczak, I. C. Tessaro, and C. P. Zapata Noreña, "Evaluation of water, sucrose and $\mathrm{NaCl}$ effective diffusivities during osmotic dehydration of banana (Musa sapientum, shum.)," LWT - Food Science and Technology, vol. 44, pp. 82-91, 2011/01/01/ 2011.

[27] K. Renu, R. Shukla, and T. Joshi, "Mass transfer during osmotic dehydration of banana slices for drying process," Int. J. Sci. Res. Publ., vol. 2, pp. 1-6, 2012.

[28] Z. Farhaninejad, M. Fathi, M. Shahedi, and M. Sadeghi, "Osmotic Dehydration of Banana Slices Using Direct and Indirect Sonication: Optimization and Microstructure Analysis," Journal of Food Process Engineering, vol. 40, p. e12336, 2017.

[29] S. Wani, V. Sharma, and P. Kumar, "Effect of processing parameters on quality attributes of fried banana chips," International Food Research Journal, vol. 24, p. 1407, 2017.

[30] M. Krokida, V. Oreopoulou, and Z. Maroulis, "Effect of frying conditions on shrinkage and porosity of fried potatoes," Journal of Food Engineering, vol. 43, pp. 147-154, 2000.

[31] A. Kita, G. Lisińska, and G. Gołubowska, "The effects of oils and frying temperatures on the texture and fat content of potato crisps," Food chemistry, vol. 102, pp. 1-5, 2007.

[32] S. Aida, A. Noriza, M. Haswani, and S. Mya, "A study on reducing fat content of fried banana chips using a sweet pretreatment technique," International Food Research Journal, vol. 23, p. 68, 2016.

[33] A. Diaz, A. M. Torres, E. Alvarez, A. Fernandez, and D. Dufour, "Influencia varietal del plátano en los procesos de deshidratación osmótica y fritura," 2008.

[34] J. Singthong and C. Thongkaew, "Using hydrocolloids to decrease oil absorption in banana chips," LWT - Food Science and Technology, vol. 42, pp. 1199-1203, 2009/09/01/ 2009.

[35] M. K. Krokida, V. T. Karathanos, and Z. B. Maroulis, "Effect of osmotic dehydration on color and sorption characteristics of apple and banana," Drying Technology, vol. 18, pp. 937-950, 2000/04/01 2000 .

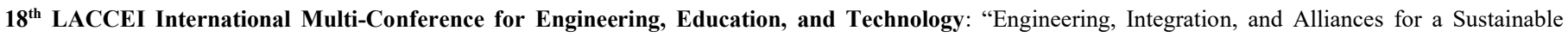
Development" "Hemispheric Cooperation for Competitiveness and Prosperity on a Knowledge-Based Economy", 29-31 July 2020, Buenos Aires, Argentina. 7 